\title{
The Vasopressin Ib Receptor Antagonist A-9883I5 Blocks Stress Effects on the Retrieval of Object-Recognition Memory
}

\author{
Areg Barsegyan 1,2,5 Piray Atsak ${ }^{1,2,5}$, Wilfried B Hornberger ${ }^{3}$, Peer B Jacobson ${ }^{4}$, Marcel M van Gaalen ${ }^{3}$ and \\ Benno Roozendaal ${ }^{*, 1,2}$ \\ 'Department of Cognitive Neuroscience, Radboud University Medical Centre, Nijmegen, The Netherlands; ${ }^{2}$ Donders Institute for Brain, Cognition \\ and Behaviour, Radboud University Nijmegen, Nijmegen, The Netherlands; ${ }^{3}$ Neuroscience Research, AbbVie Deutschland GmbH \& Co KG, \\ Ludwigshafen, Germany; ${ }^{4}$ Integrated Sciences and Technology, Imaging Research, AbbVie, North Chicago, IL, USA
}

\begin{abstract}
Stress-induced activation of the hypothalamo-pituitary-adrenocortical (HPA) axis and high circulating glucocorticoid levels are well known to impair the retrieval of memory. Vasopressin can activate the HPA axis by stimulating vasopressin Ib (VIb) receptors located on the pituitary. In the present study, we investigated the effect of A-9883I5, a selective and highly potent non-peptidergic $V I$ b-receptor antagonist with good pharmacokinetic properties, in blocking stress effects on HPA-axis activity and memory retrieval. To study cognitive performance, male Sprague-Dawley rats were trained on an object-discrimination task during which they could freely explore two identical objects. Memory for the objects and their location was tested $24 \mathrm{~h}$ later. A-988315 (20 or $60 \mathrm{mg} / \mathrm{kg}$ ) or water was administered orally $90 \mathrm{~min}$ before retention testing, followed $60 \mathrm{~min}$ later by stress of footshock exposure. A-9883 5 dose-dependently dampened stressinduced increases in corticosterone plasma levels, but did not significantly alter HPA-axis activity of non-stressed control rats. Most importantly, A-988315 administration prevented stress-induced impairment of memory retrieval on both the object-recognition and the object-location tasks. A-9883 I 5 did not alter the retention of non-stressed rats and did not influence the total time spent exploring the objects or experimental context in either stressed or non-stressed rats. Thus, these findings indicate that direct antagonism of $\mathrm{VIb}$ receptors is an effective treatment to block stress-induced activation of the HPA axis and the consequent impairment of retrieval of different aspects of recognition memory.
\end{abstract}

Neuropsychopharmacology (20I5) 40, 1979-1989; doi:I0.I038/npp.20I5.48; published online 4 March 2015

\section{INTRODUCTION}

Stress exposure leads to an activation of the sympathetic nervous system and hypothalamo-pituitary-adrenocortical (HPA) axis, culminating in the release of catecholamines and glucocorticoids, respectively (Joëls and Baram, 2009). These hormones are known to influence the organism's ability to cope with stress, influencing target systems in the periphery, but also inducing a myriad of effects on the brain (McEwen, 1998; de Kloet et al, 1999; McGaugh and Roozendaal, 2002). Extensive evidence indicates that stress enhances the consolidation, but impairs the retrieval, of memory processing (reviewed in Roozendaal et al, 2009; Schwabe et al, 2012). Although the exact biological function of stressinduced impairment of memory retrieval remains obscure (Roozendaal, 2002), memory retrieval deficits, as a result of acute or chronic stress exposure, can have marked negative consequences for the normal cognitive functioning of an

*Correspondence: Professor B Roozendaal, Department of Cognitive Neuroscience, Radboud University Medical Centre, Geert Grooteplein Noord 21, PO Box 910I, Nijmegen 6500 HB, The Netherlands, Tel: +3I (0) 24366 630।, E-mail: Benno.Roozendaal@radboudumc.nl ${ }^{5}$ These two authors contributed equally to this work.

Received 7 January 2015; revised 3 February 2015; accepted 3 February 20।5; accepted article preview online II February 2015 individual (de Quervain et al, 2009). As the suppression of glucocorticoid synthesis with the $11 \beta$-hydroxylase inhibitor metyrapone prevents the impairing effect of stress exposure on memory retrieval (de Quervain et al, 1998), these findings indicate that activation of the HPA axis and high circulating glucocorticoid levels are importantly involved in mediating stress effects on memory retrieval. This view is supported by extensive evidence that acute glucocorticoid administration before retention testing induces comparable retrieval impairment of declarative memory in humans and spatial/contextual memory in rodents (de Quervain et al, 1998, 2000; Roozendaal et al, 2003; Het et al, 2005; Kuhlmann et al, 2005; Atsak et al, 2012). For decades, the predominant view held that stress has a specific and particularly robust influence on the hippocampus (McEwen and Sapolsky, 1995; Lupien and Lepage, 2001). However, there is now emerging evidence that stress and glucocorticoids might also affect retrieval of non-hippocampal memories. A recent study indicated that stress exposure impairs retrieval of striatal-dependent stimulus-response memory in humans (Guenzel et al, 2013). Whether and how stress exposure might also impair the retrieval of recognition memory remains largely elusive. In the present study, we used an object-discrimination task to investigate, in rats, whether stress exposure shortly before retention testing 
impairs recognition of different aspects of information acquired during the training phase. Specifically, the task required discrimination of a novel $v s$ familiar object or novel vs familiar object location. Memory for the location of an object depends on the hippocampus, whereas memory for an object per se is known to rely heavily on cortical regions (Balderas et al, 2008; Roozendaal et al, 2010).

Numerous neurotransmitter and neuropeptide systems, originating from local, brainstem, and limbic sources, are involved in modulating HPA-axis activity during stressful conditions (Rossier et al, 1979; Herman et al, 1996). Arginine vasopressin (AVP) is a cyclic peptide that is synthesized in the hypothalamus, and it strongly contributes to the endocrine response to stress (Surget and Belzung, 2008). During stress exposure, AVP is released from the median eminence into the pituitary portal circulation where it potentiates the effects of corticotropin-releasing factor on adrenocorticotropin (ACTH) release, which in turn stimulates glucocorticoid release from the adrenal cortex (Aguilera and Rabadan-Diehl, 2000). Antagonism of vasopressin 1b (V1b) receptors has been reported to attenuate stressinduced HPA-axis activation (Serradeil-Le Gal et al, 2005). The primary focus of this study was to investigate whether attenuating HPA-axis activity with the orally active nonpeptidergic V1b-receptor antagonist A-988315 is sufficient to block stress effects on memory retrieval. In contrast to adrenal steroidogenesis inhibition with metyrapone, which elevates ACTH levels triggered by reduced HPA-axis feedback regulation (Gómez et al, 1998), direct inhibition of the HPA axis with A-988315 is expected to decrease both ACTH and corticosterone levels. This distinction might be pertinent as some evidence indicates that ACTH release or exogenous ACTH administration by itself can enhance memory retrieval (Izquierdo et al, 2002; Gisquet-Verrier et al, 2004). As A-988315, (S)-N-(5-chloro-1-((2,4-dimethoxyphenyl)sulfonyl)-3-(2-ethoxypyridin-3-yl)-2-oxoindolin-3-yl)4-(1-methylpiperidin-4-yl)piperazine-1-carboxamide, is a recently developed V1b-receptor antagonist, we also determined the specificity of A-988315 in binding to rat and human V1b, V1a, V2, and oxytocin receptors in vitro, and its ability to antagonize functional cellular events associated with V1b-receptor activation by AVP, such as intracellular $\mathrm{Ca}^{2+}$ release (Serradeil-Le Gal et al, 2002). Moreover, we evaluated the pharmacokinetic properties of the drug after oral and intraperitoneal administration.

\section{MATERIALS AND METHODS}

\section{Subjects}

Male Sprague-Dawley rats (360-420 g at the time of training) from Charles River Breeding Laboratories (Kisslegg, Germany) were housed individually in a temperature-controlled $\left(22^{\circ} \mathrm{C}\right)$ vivarium room (lights on: 07:00-19:00 hours) and given food and water ad libitum. Training and testing were performed during the light phase of the cycle between 10:00 and 15:00 hours, at the rat's nadir of endogenous corticosterone levels. All experimental procedures were in compliance with the European Communities Council Directive of 24 November 1986 (86/609/EEC) and approved by the Institutional Animal Care and Use Committee.

\section{Object Training and Testing Procedures}

The experimental apparatus was a gray open-field box (in $\mathrm{cm}$, 40 wide $\times 40$ deep $\times 40$ high) with the floor covered with sawdust, positioned in a dimly illuminated room. The objects to be discriminated were transparent glass vials $(5.5 \mathrm{~cm}$ diameter and $5 \mathrm{~cm}$ height $)$ and white glass light bulbs $(6 \mathrm{~cm}$ diameter and $11 \mathrm{~cm}$ length; Okuda et al, 2004; Roozendaal et al, 2010).

All rats were handled once per day for $1 \mathrm{~min}$ each for 5 consecutive days preceding the training day. On the training trial, each rat was individually placed in the experimental apparatus and allowed to explore two identical objects (A1 and A2) for $10 \mathrm{~min}$. To avoid the presence of olfactory cues, the sawdust was stirred and the objects were cleaned with $70 \%$ ethanol after each animal. Rats' behavior was recorded with a video camera positioned above the experimental apparatus. Videos were later analyzed by a trained observer who is blind to the treatment condition. The total time spent exploring the two objects during the training trial was taken as a measure of object exploration. Rats showing a total exploration time $<20 \mathrm{~s}$ on the training trial were removed from analyses, because data indicated that such rats do not acquire the task (Okuda et al, 2004).

Retention was tested $24 \mathrm{~h}$ after the training trial. Different groups of rats were tested on the object-recognition and object-location tasks. For object-recognition memory testing, one copy of the familiar object (A3) and a new object (B) were placed in the same location as stimuli during the training trial. For object-location memory testing, one copy of the familiar object (A3) was placed in the middle of the box (novel location) and the other familiar object (A4) was placed in the same location as during the training trial. All combinations and locations of the objects were counterbalanced to reduce potential biases owing to preference for particular locations or objects. The rat was placed in the experimental apparatus for $3 \mathrm{~min}$, and the time spent exploring each object and the total time spent exploring both objects were recorded. Exploration of an object was defined as pointing the nose to the object at a distance of $<1 \mathrm{~cm}$ and/or touching it with the nose. Turning around, climbing or sitting on an object was not considered as exploration. In order to analyze cognitive performance, a discrimination index was calculated as the difference in time exploring the novel and familiar object (or location), expressed as the ratio of the total time spent exploring both objects (ie, (time novel - time familiar/time novel+time familiar) $\times 100 \%$ ). Exploration of the experimental apparatus was analyzed by the total number of crossings. For crossings, the floor of the box was divided into four imaginary quadrants, and the total number of crossings between quadrants during the 3-min retention test trial was determined.

\section{Oral Drug Administration}

A-988315 (20 or $60 \mathrm{mg} / \mathrm{kg}$, free base concentration) or water, in a volume of $2 \mathrm{ml} / \mathrm{kg}$, was orally gavaged $90 \mathrm{~min}$ before the retention test. A-988315 was dissolved in water.

\section{Stress Procedure}

Some rats were exposed to stress of footshock $30 \mathrm{~min}$ before retention testing (60 min after drug administration). We selected this time point on the basis of prior evidence 
that this stress procedure triggers an HPA-axis response that leads to a corticosterone plasma peak at $\approx 30 \mathrm{~min}$ (de Quervain et al, 1998). ACTH, which is not expected to contribute significantly to stress-induced memory retrieval impairment, reaches its peak earlier (Sarabdjitsingh et al, 2010). Rats were taken from their home cage and placed into the shock compartment of an inhibitory avoidance apparatus. The shock compartment $(60 \mathrm{~cm}$ long, $15 \mathrm{~cm}$ deep, $20 \mathrm{~cm}$ wide at the top, and $6.4 \mathrm{~cm}$ wide at the bottom) was made of two electrifiable metal plates (de Quervain et al, 1998). The rats were given a series of three inescapable footshocks $(0.8 \mathrm{~mA}, 1 \mathrm{~s}$ in duration with an intertrial interval of $5 \mathrm{~s}$ ). Both drug- and water-treated rats showed strong reactions to the footshocks and exhibited jumping, running, and vocalizations. Immediately after delivery of the last footshock, rats were placed back into their home cage until the retention test $30 \mathrm{~min}$ later. Non-stressed control rats did not receive footshock and were left undisturbed in their home cages until retention testing.

\section{Plasma Collection, and ACTH and Corticosterone Assessment}

Immediately after retention testing, rats were anesthetized with sodium pentobarbital and decapitated 90 s later. Trunk blood was collected in chilled tubes containing $30 \mu \mathrm{l}$ aprotinin (Sigma-Aldrich) and EDTA $(1.86 \mathrm{mg} / \mathrm{ml} \mathrm{blood).}$ Blood was immediately centrifuged at $2900 \mathrm{~g}$ for $10 \mathrm{~min}$ at $4^{\circ}$ $\mathrm{C}$, and the supernatant was stored at $-80^{\circ} \mathrm{C}$.

ACTH concentrations were measured by an enzyme-linked immunosorbent assay (ELISA; IBL Hamburg, Germany). Before ELISA analysis, samples were diluted 2.5-fold with calibrator A (Zero Calibrator; IBL Hamburg, Germany) provided with the ELISA kit. Corticosterone concentrations were determined with an enzyme immunoassay (EIA; Cayman chemical, purchased from Alexis $\mathrm{GmbH}$, Grünberg, Germany). Plasma samples were diluted 10-fold with EIA buffer $\left(0.2 \mathrm{M} \mathrm{Na}_{2} \mathrm{HPO}_{4}\right.$, $0.8 \mathrm{M} \mathrm{NaCl}, 2 \mathrm{mM}$ Na-EDTA, $0.2 \% \mathrm{w} / \mathrm{v}$ bovine serum albumin (BSA)) for the corticosterone assay. The intra- and inter-assay coefficients of variation for ACTH and corticosterone were $<10 \%$. The analytical sensitivity for ACTH was $0.46 \mathrm{pg} / \mathrm{ml}$ and for corticosterone was $30 \mathrm{pg} / \mathrm{ml}$.

\section{Statistics}

Object-recognition training and retention data, and ACTH and corticosterone plasma levels are expressed as mean \pm SEM. Two-way ANOVAs for discrimination index, total object exploration, number of crossings, and plasma ACTH and corticosterone levels were analyzed with A-988315 treatment and stress procedure as between-subject variables. Further analyses used Fisher's post-hoc comparison tests to determine the source of the detected significance, when appropriate. Onesample $t$-tests were used to determine whether the discrimination index was different from zero (ie, chance level) and thus whether memory was expressed. A probability level of $<0.05$ was accepted as statistical significance for all the tests.

\section{In Vitro Binding and Functional Studies, and Pharmacokinetics}

Full procedures are described in Supplementary Materials and Methods. Briefly, radioligand competition-binding assays for cloned human and rat V1b receptors were performed using [3H]-AVP (8-Arg-Vasopressin NET800, PerkinElmer, Boston) as radioligand, and membranes or cell ghosts prepared from Chinese hamster ovary (CHO) cell clones stably expressing the recombinant human and rat receptors. Recombinant cell membranes were incubated with $1.5 \mathrm{nM}$ (human) and $1.0 \mathrm{nM}$ (rat) [3H]-AVP for competition experiments, performed in a $50-\mathrm{mM}$ Tris buffer, $\mathrm{pH} 7.4$, containing $10 \mathrm{mM} \mathrm{MgCl}_{2}$ and $0.1 \% \mathrm{BSA}$ without or in the presence of A-988315 $(0.1 \mathrm{nM}-10 \mu \mathrm{M})$. AVP $(1 \mu \mathrm{M})$ was used for determination of nonspecific binding. Radioactivity was measured by liquid scintillation counting (Tri-Carb, PerkinElmer, Boston). Other radioligand assays were performed for human or rat V1a receptors, human V2 receptors, and human or rat oxytocin receptors. Ki values from competition-binding experiments were determined by nonlinear regression analysis (Munson and Rodbard, 1980).

For the assessment of antagonistic potency of A-988315, recombinant human $\mathrm{V} 1 \mathrm{~b}$ receptor-expressing $\mathrm{CHO}$ cells were seeded into FLIPR plates (Falcon 384 plate \#353962, Becton Dickinson) and incubated overnight. Stimulation of $\mathrm{Ca}^{2+}$ release was performed with 2 nM AVP. A-988315 (at the desired concentrations) was pre-incubated for $10 \mathrm{~min}$ before agonist addition. Measurements were performed using a FLIPR2 reader (Molecular Devices, Sunnyvale).

To estimate the pharmacokinetic properties of A-988315 in terms of oral bioavailability, half-life and brain-to-plasma ratio, male Sprague-Dawley rats $(n=3$; Janvier, Le Genest-StIsle, France) were injected intravenously $(2 \mathrm{mg} / \mathrm{kg}$ ) or orally gavaged $(10 \mathrm{mg} / \mathrm{kg})$ with A-988315 dissolved in water. Blood was sampled from the tail vein after $30 \mathrm{~min}, 45 \mathrm{~min}, 1,2,2.5$, $3,4,6,8$, and $24 \mathrm{~h}$. For the brain distribution study, rats ( $n=3$ for each time point) were injected intraperitoneally with $10 \mathrm{mg} / \mathrm{kg}$ of A-988315. After $30 \mathrm{~min}, 3 \mathrm{or} 8 \mathrm{~h}$, the rats were deeply anesthetized with isoflurane, and blood was drawn via cardiac puncture. The animal was sacrificed by cervical dislocation, and the brain was removed. Plasma samples and brains were stored at $-18{ }^{\circ} \mathrm{C}$ until analysis. An aliquot of plasma or homogenized whole-brain tissue was pipetted into a 96-well polypropylene plate, and proteins were precipitated with acetonitrile containing an internal standard. The plate was centrifuged at $2000 \mathrm{~g}$ for $10 \mathrm{~min}$ and the supernatant was transferred to a clean 96-well plate and diluted 1:1 with $0.1 \%$ formic acid. Samples were injected on an Acquity UPLC BEH C8 $1.7 \mu \mathrm{m}, 2.1 \times 100 \mathrm{~mm}$ with an acetonitrile gradient (5-95\%) with $0.1 \%$ formic acid (in water) as the second solvent, at a flow rate of $0.3 \mathrm{ml} / \mathrm{min}$. Mass-spectrometric detection was performed on an $\mathrm{AB}$ SCIEX Triple Quad 5500 with a turbo-ion spray interface by multiple-reaction monitoring. Oral bioavailability and brain exposure were determined by comparing the area under the curve (AUC) from zero to the final time point measured (AUC0-t) of the two compartments.

\section{RESULTS}

\section{In Vitro Binding Studies}

A-988315 displayed high affinity in radioligand-binding assays for cloned human (Figure 1a) and rat (Figure 1b) vasopressin $\mathrm{V} 1 \mathrm{~b}$ receptors. The $\mathrm{Ki}$ values (geomeans and 95\% CI) for the human $\mathrm{V} 1 \mathrm{~b}, \mathrm{~V} 1 \mathrm{a}$, and $\mathrm{V} 2$ receptors, and the 


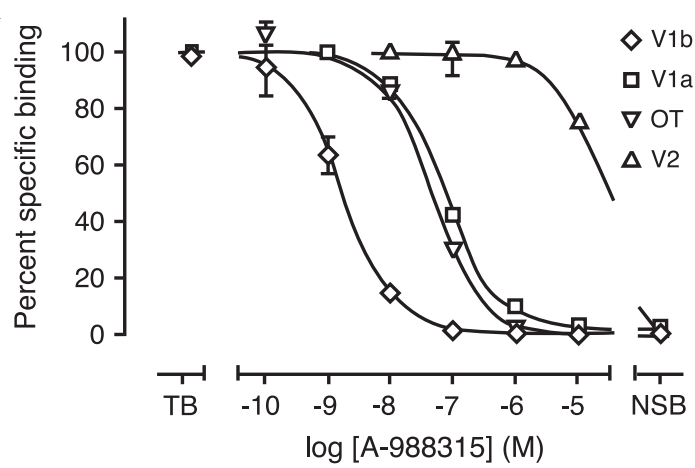

C

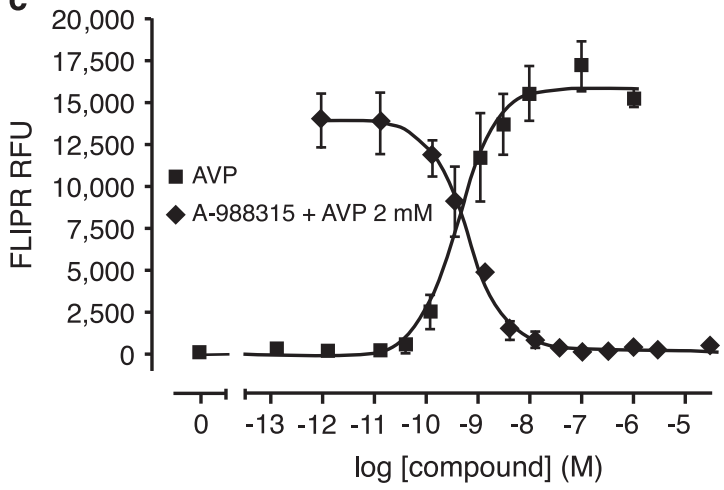

b
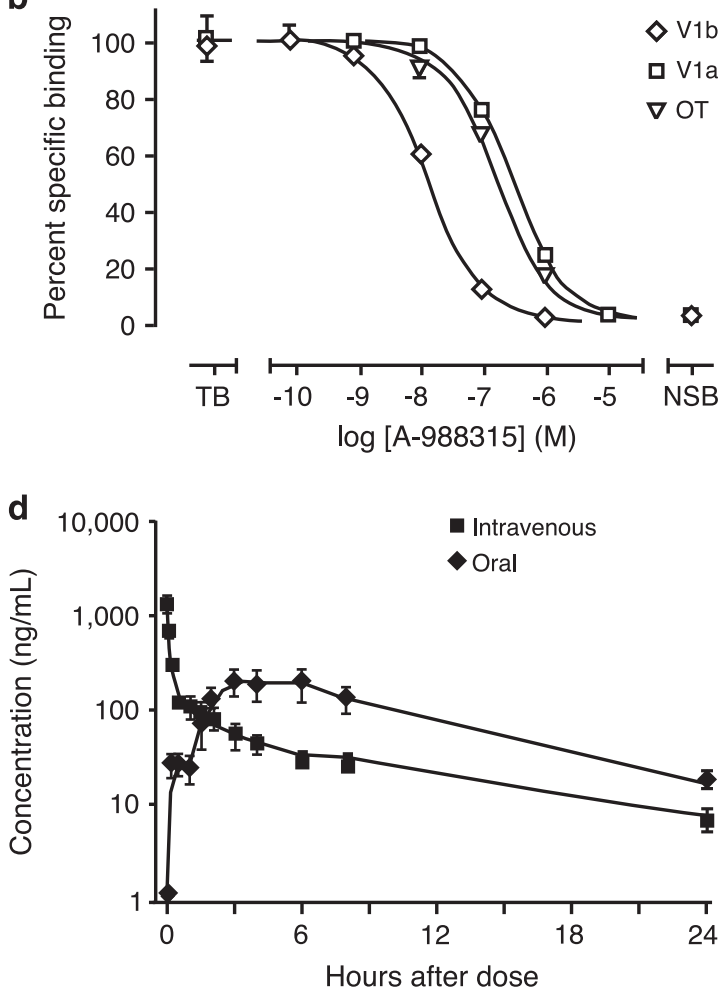

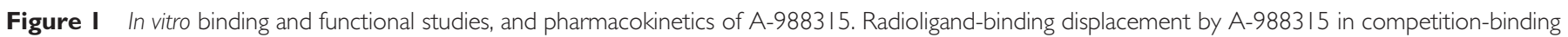

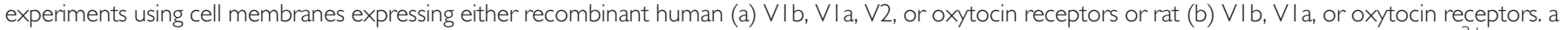

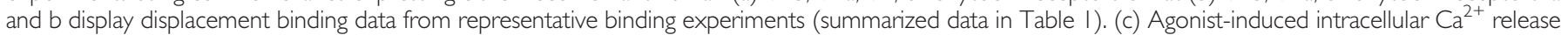

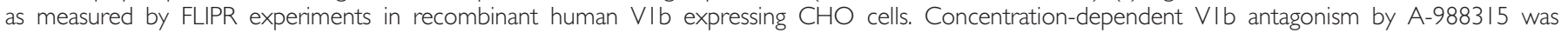

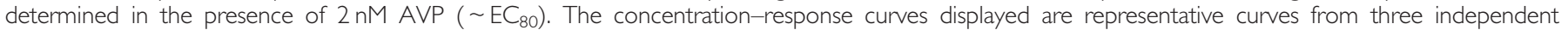
experiments. (d) Time-dependent plasma concentrations of A-9883 I5 after intravenous $(2 \mathrm{mg} / \mathrm{kg})$ or oral (I0 mg/kg) administration in rats.

Table I Affinity of A-9883I5 in Binding to Human and Rat Vasopressin VIb, VIa, V2 Receptors, and Oxytocin Receptors

\begin{tabular}{|c|c|c|c|c|}
\hline \multirow[b]{2}{*}{ Species } & \multicolumn{4}{|c|}{ Ki values (nM, geomeans, and $95 \% \mathrm{Cl}, \mathrm{n}=4$ ) } \\
\hline & VIb & Vla & V2 & От \\
\hline Human & $0.53(0.39-0.7 I)$ & $50(32-62)$ & $>10000$ & $8.3(6.8-10)$ \\
\hline Rat & $3.8(2.7-5.4)$ & $121(102-|4|)$ & Not determined & $90(77-100)$ \\
\hline
\end{tabular}

Abbreviations: $\mathrm{Cl}$, confidence interval; OT, oxytocin.

Ki values ( $n M$, geomeans and $95 \% \mathrm{Cl}, n=4)$ obtained in radioligand displacement assays using membranes expressing recombinant rat or human receptors.

oxytocin receptor were $0.53 \quad(0.39-0.71), 50$ (32-62), $>10000$, and $8.3(6.8-10) \mathrm{nM}$, respectively (Table 1). The $\mathrm{Ki}$ values for the rat $\mathrm{V} 1 \mathrm{~b}$ and V1a receptors and the oxytocin receptor were 3.8 (2.7-5.4), 121 (102-141), and 90 (77-100) nM (Table 1), respectively. Thus, the Ki value for the rat $\mathrm{V} 1 \mathrm{~b}$ receptor was sevenfold above that of the human V1b receptor. The Hill slopes derived from the inhibition-binding curves with the cloned human and rat $\mathrm{V} 1 \mathrm{~b}$ receptors were close to unity, suggesting a single site of interaction of A-988315 and radioligand in these membrane preparations.

\section{Intracellular $\mathrm{Ca}^{2+}$ Release}

Antagonistic properties of A-988315 were assessed in recombinant $\mathrm{CHO}$ cells expressing the human V1b receptor. As shown in Figure 1c, A-988315 antagonized the AVPmediated $\mathrm{Ca}^{2+}$ release in a concentration-dependent manner with a $\mathrm{Kb}$ value, as a measure of competitive antagonist potency, of $0.10 \mathrm{nM}$ (geomean, 95\% CI: 0.062-0.15 nM, $n=3)$.

\section{Pharmacokinetic Studies}

A-988315 demonstrated good pharmacokinetic properties. The oral bioavailability of the compound was $50 \pm 14 \%$ $(n=3)$. After a single $10-\mathrm{mg} / \mathrm{kg}$ oral dose, A-988315 reached a maximal plasma concentration of $228 \pm 59 \mathrm{ng} / \mathrm{ml}$ (Figure 1d). Estimated plasma half-life of A-988315 was $5.6 \pm 0.7 \mathrm{~h}$. The brain:plasma ratio calculated over an 8 -h time period was 0.32 .

\section{Behavioral Studies}

Effect of A-988315 on stress-induced impairment of retrieval of object-recognition memory. This experiment investigated whether oral administration of A-988315 would block stress-induced impairment of retrieval of objectrecognition memory. For this, rats were exposed to a single 
a
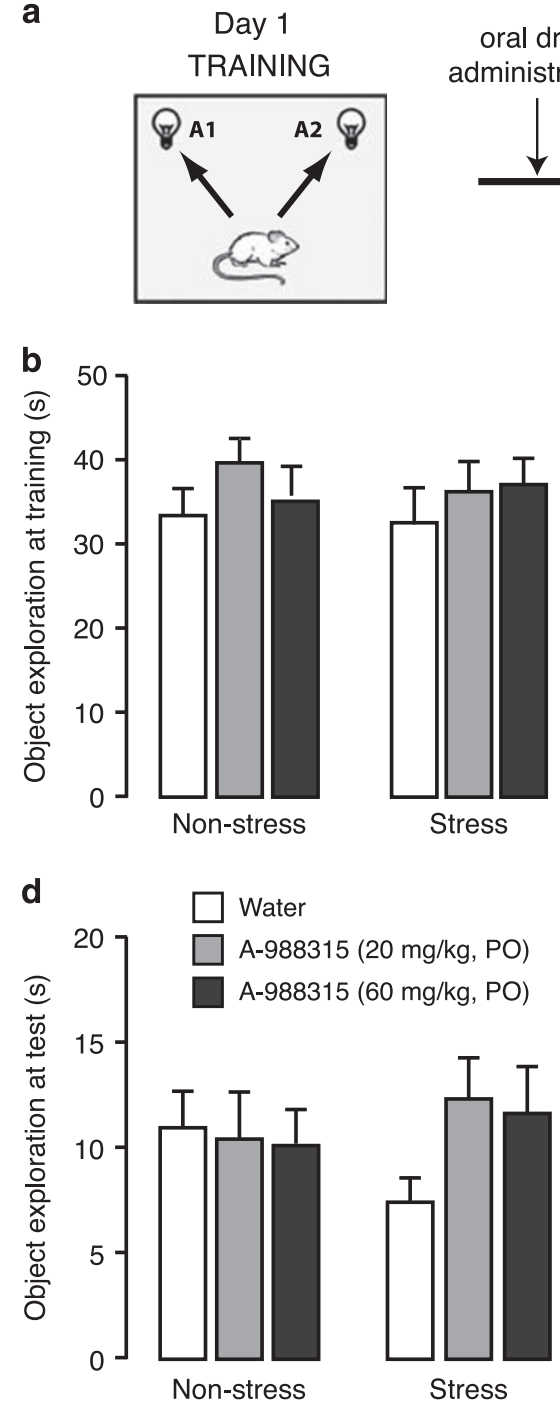

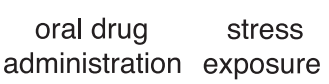

Day 2 TESTING
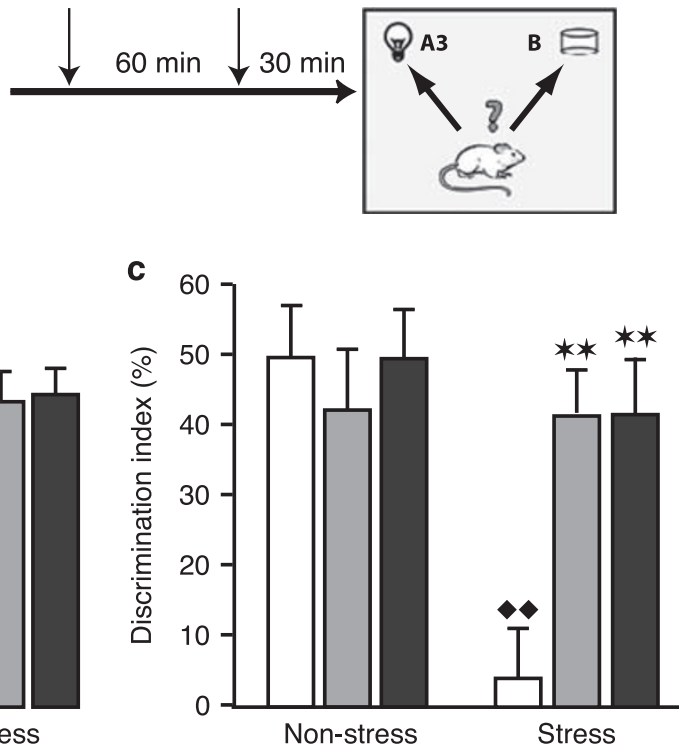

e

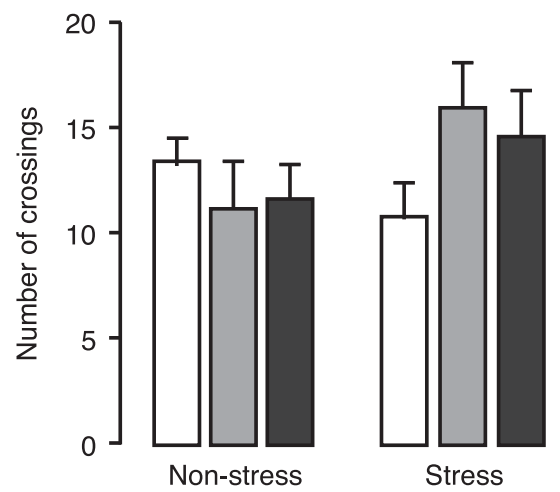

Figure 2 Effect of pretest administration of A-9883I5 on stress-induced impairment of retrieval of object-recognition memory. (a) Schematic illustration of training procedure, and drug and stress exposure. (b) Total time (in s) spent exploring both identical objects during the I0-min training session, before drug administration or stress exposure. (c) Discrimination index (in \%) during the 3-min retention test trial. (d) Total time (in s) spent exploring both objects during the retention test trial. (e) Total number of quadrant crossings during the retention test trial as a measure of exploration of the experimental context. All data are expressed as mean+SEM. $* * P<0.01$ compared with the corresponding water group. ${ }^{*} p<0.01$ compared with the corresponding non-stress group. Number of rats per group-non-stress groups: water, $n=11 ; 20 \mathrm{mg} / \mathrm{kg}, n=11$; and $60 \mathrm{mg} / \mathrm{kg}, n=10$; and stress groups: water, $n=10 ; 20 \mathrm{mg} / \mathrm{kg}, n=9$; and $60 \mathrm{mg} / \mathrm{kg}, \mathrm{n}=10$.

10-min training trial during which they could freely explore two identical objects. Retention of the training was tested $24 \mathrm{~h}$ later. A-988315 (20 or $60 \mathrm{mg} / \mathrm{kg}$ ) or water was administered $90 \mathrm{~min}$ before retention testing. Some rats were exposed to stress of footshock $30 \mathrm{~min}$ before retention testing. During the retention test, one object was familiar and the other object was novel. Figure $2 \mathrm{a}$ shows the timeline of the object-recognition experiment.

Training trial. Figure $2 \mathrm{~b}$ shows the total time spent exploring the two identical objects during the 10-min training trial (before drug treatment or shock exposure). As expected, two-way ANOVA indicated no differences between later drug treatment $\left(F_{2,55}=1.12\right.$; NS), stress exposure $\left(F_{1,55}=0.08\right.$;
NS), or an interaction between these two parameters $\left(F_{2,55}=0.27 ; \mathrm{NS}\right)$.

Retention trial. Figure $2 \mathrm{c}$ shows the discrimination index during the retention test trial. Two-way ANOVA indicated a significant A-988315 effect $\left(F_{2,55}=3.61 ; P=0.03\right)$, stress-exposure effect $\left(F_{1,55}=9.10 ; P=0.004\right)$ as well as a significant interaction between these two parameters $\left(F_{2,55}=5.14 ; P=0.009\right)$. One-sample $t$-test indicated that the discrimination index of non-stressed control rats administered water before retention testing was significantly different from zero (ie, chance level, $t_{10}=6.73 ; P=0.0001$ ), indicating that these rats readily discriminated the novel object at the $24-\mathrm{h}$ retention test. A-988315 (20 or $60 \mathrm{mg} / \mathrm{kg}$ ) 
did not significantly alter the discrimination index of nonstressed rats $(P \geqslant 0.55)$. Water-treated rats that were subsequently exposed to stress of footshock $30 \mathrm{~min}$ before retention testing showed impaired recognition of the familiar object as compared with water-treated non-stressed rats $(P=0.0003)$. One-sample $t$-test indicated that the discrimination index of water-treated stressed rats did not differ significantly from zero $\left(t_{9}=0.57 ; P=0.58\right)$, indicating that they did not show any evidence of retention of the training session. Most importantly, both doses of A-988315 (20 or $60 \mathrm{mg} / \mathrm{kg}$ ) normalized the discrimination index of stressed rats $(20 \mathrm{mg} / \mathrm{kg}: P=0.001 ; 60 \mathrm{mg} / \mathrm{kg}: P=0.001$ vs water), which did not differ significantly from that of non-stressed rats. Further, one-sample $t$-tests indicated that the discrimination index of stressed rats administered A-988315 was significantly different from zero $\left(20 \mathrm{mg} / \mathrm{kg}\right.$ : $t_{8}=6.47$; $\left.P=0.0002 ; 60 \mathrm{mg} / \mathrm{kg}: t_{9}=5.31 ; P=0.0005\right)$, indicating good retention performance.

Figure 2d shows total exploration of the two objects during the retention test. Two-way ANOVA indicated no significant A-988315 effect $\left(F_{2,55}=0.75 ; \mathrm{NS}\right)$, stress-exposure effect $\left(F_{1,55}=0.00 ; \mathrm{NS}\right)$ or an interaction between these two parameters $\left(F_{2,55}=1.24\right.$; NS). Similarly, two-way ANOVA for the number of quadrant crossings during the retention test trial, as a measure of exploration of the experimental apparatus, also indicated no significant A-988315 effect $\left(F_{2,55}=0.31 ; \mathrm{NS}\right)$, stress-exposure effect $\left(F_{1,55}=1.21 ; \mathrm{NS}\right)$ or interaction between these two parameters $\left(F_{2,55}=2.22\right.$; NS; Figure 2e).

Effect of A-988315 on stress-induced impairment of retrieval of object-location memory. This experiment investigated, in separate groups of rats, whether oral administration of A-988315 would block stress-induced impairment of retrieval of object-location memory. For this, rats were exposed, as in the first experiment, to a 10-min training trial during which they could freely explore two identical objects. Retention of the training was tested $24 \mathrm{~h}$ later. A-988315 (20 or $60 \mathrm{mg} / \mathrm{kg}$ ) or water was administered $90 \mathrm{~min}$ before retention testing, followed $60 \mathrm{~min}$ later by stress exposure. During the retention test, both objects were familiar, but one object was placed in a novel location. Figure 3 a shows the timeline of the object-location experiment.

Training trial. Figure $3 \mathrm{~b}$ shows the total time spent exploring the two identical objects during the 10-min training trial (before drug treatment or shock exposure). Two-way ANOVA indicated no differences between later drug-treatment groups $\left(F_{2,57}=0.99 ; \mathrm{NS}\right)$, stress-exposure effect $\left(F_{1,57}=0.75\right.$; NS) or an interaction between these two parameters $\left(F_{2,57}=0.71\right.$; NS).

Retention trial. Figure $3 \mathrm{c}$ shows the discrimination index during the retention test trial. Two-way ANOVA indicated no significant stress-exposure effect $\left(F_{1,57}=2.54\right.$; NS), but a significant A-988315 effect $\left(F_{2,57}=3.65 ; P=0.03\right)$ as well as a significant interaction between these two parameters $\left(F_{2,57}=5.93 ; P=0.005\right)$. One-sample $t$-test indicated that the discrimination index of non-stressed control rats administered water before retention testing was significantly different from zero $\left(t_{9}=3.50 ; P=0.007\right)$, indicating that these rats readily discriminated the object placed in a novel location. A-988315 (20 or $60 \mathrm{mg} / \mathrm{kg}$ ) did not significantly alter the discrimination index of non-stressed rats $(P \geqslant 0.41)$. Water-treated rats that were subsequently exposed to stress of footshock ( $30 \mathrm{~min}$ before retention testing) showed impaired recognition of the location of objects during training $(P=0.003$ vs water $)$. One-sample $t$-test indicated that the discrimination index of water-treated stressed rats did not differ significantly from zero $\left(t_{10}=\right.$ $-1.24 ; P=0.24)$, indicating that they did not show retention of the training. Most importantly, both doses of A-988315 (20 or $60 \mathrm{mg} / \mathrm{kg}$ ) normalized the discrimination index of stressed rats $(20 \mathrm{mg} / \mathrm{kg}: P=0.005 ; 60 \mathrm{mg} / \mathrm{kg}: P=0.0008$ vs water), and did not differ significantly from their nonstressed counterparts. Further, one-sample $t$-tests indicated that the discrimination index of stressed rats administered A-988315 was significantly different from zero $(20 \mathrm{mg} / \mathrm{kg}$ : $\left.t_{9}=3.40 ; P=0.008 ; 60 \mathrm{mg} / \mathrm{kg}: t_{10}=4.37 ; P=0.001\right)$, indicating good retention performance.

Figure 3d shows total exploration of the two objects during the retention test. Two-way ANOVA indicated no significant A-988315 effect $\left(F_{2,57}=0.67 ; \quad N S\right)$, stress-exposure effect $\left(F_{1,57}=0.62 ; \mathrm{NS}\right)$ or an interaction between these two parameters $\left(F_{2,57}=0.60 ; \mathrm{NS}\right)$. Two-way ANOVA for the number of crossings during the retention test trial also indicated no significant A-988315 effect $\left(F_{2,57}=0.72\right.$; NS), stress-exposure effect $\left(F_{1,57}=0.66 ; \mathrm{NS}\right)$ or interaction between these two parameters $\left(F_{2,57}=1.15\right.$; NS; Figure $\left.3 \mathrm{e}\right)$.

Effect of A-988315 on stress-induced increases in plasma ACTH and corticosterone levels. Immediately after either object-recognition or object-location memory testing, rats were sacrificed for collection of blood for measurement of plasma ACTH and corticosterone levels. Figure 4a shows plasma ACTH levels. Two-way ANOVA revealed a significant stress-exposure effect $\left(F_{1,118}=19.32 ; P<0.0001\right)$, but no significant A-988315 effect $\left(F_{2,118}=0.47\right.$; NS) or interaction between both factors $\left(F_{2,118}=0.79\right.$; NS). A-988315 (20 or $60 \mathrm{mg} / \mathrm{kg}$ ) did not significantly alter plasma ACTH levels of non-stressed rats $(P \geqslant 0.85)$. Water-treated rats that were subsequently exposed to stress of footshock showed significantly elevated plasma ACTH levels as compared with water-treated non-stressed rats $(P=0.004)$. A-988315 (20 or $60 \mathrm{mg} / \mathrm{kg}$ ) did not significantly reduce plasma ACTH levels as compared with water-treated stressed rats $(P \geqslant 0.12)$. However, plasma ACTH levels of stressed rats treated with the higher dose of A-988315 were not significantly higher than those of non-stressed rats treated with the same drug dose $(P=0.15)$.

Figure $4 \mathrm{~b}$ shows plasma corticosterone levels. Two-way ANOVA indicated no significant drug effect $\left(F_{2,117}=0.61\right.$; NS), but a significant stress-exposure effect $\left(F_{1,117}=38.96\right.$; $P<0.0001)$ and interaction between both factors $\left(F_{2,117}=3.98\right.$; $P=0.02)$. A-988315 (20 or $60 \mathrm{mg} / \mathrm{kg}$ ) did not significantly alter plasma corticosterone levels of non-stressed rats $(P \geqslant 0.21)$. Water-treated rats that were subsequently exposed to stress of footshock showed significantly elevated plasma corticosterone levels as compared with water-treated nonstressed rats $(P<0.0001)$. A-988315 dose-dependently decreased plasma corticosterone levels in stressed rats $(20 \mathrm{mg} / \mathrm{kg}$ : $P=0.16 ; 60 \mathrm{mg} / \mathrm{kg}: \quad P=0.01)$. Plasma corticosterone levels 

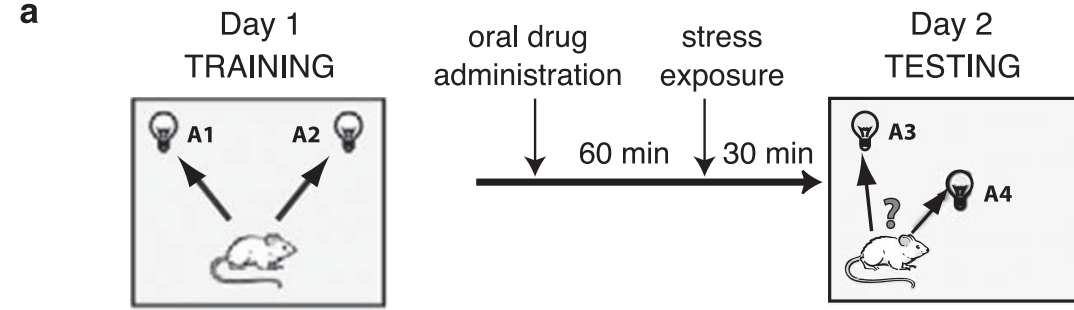

Day 2
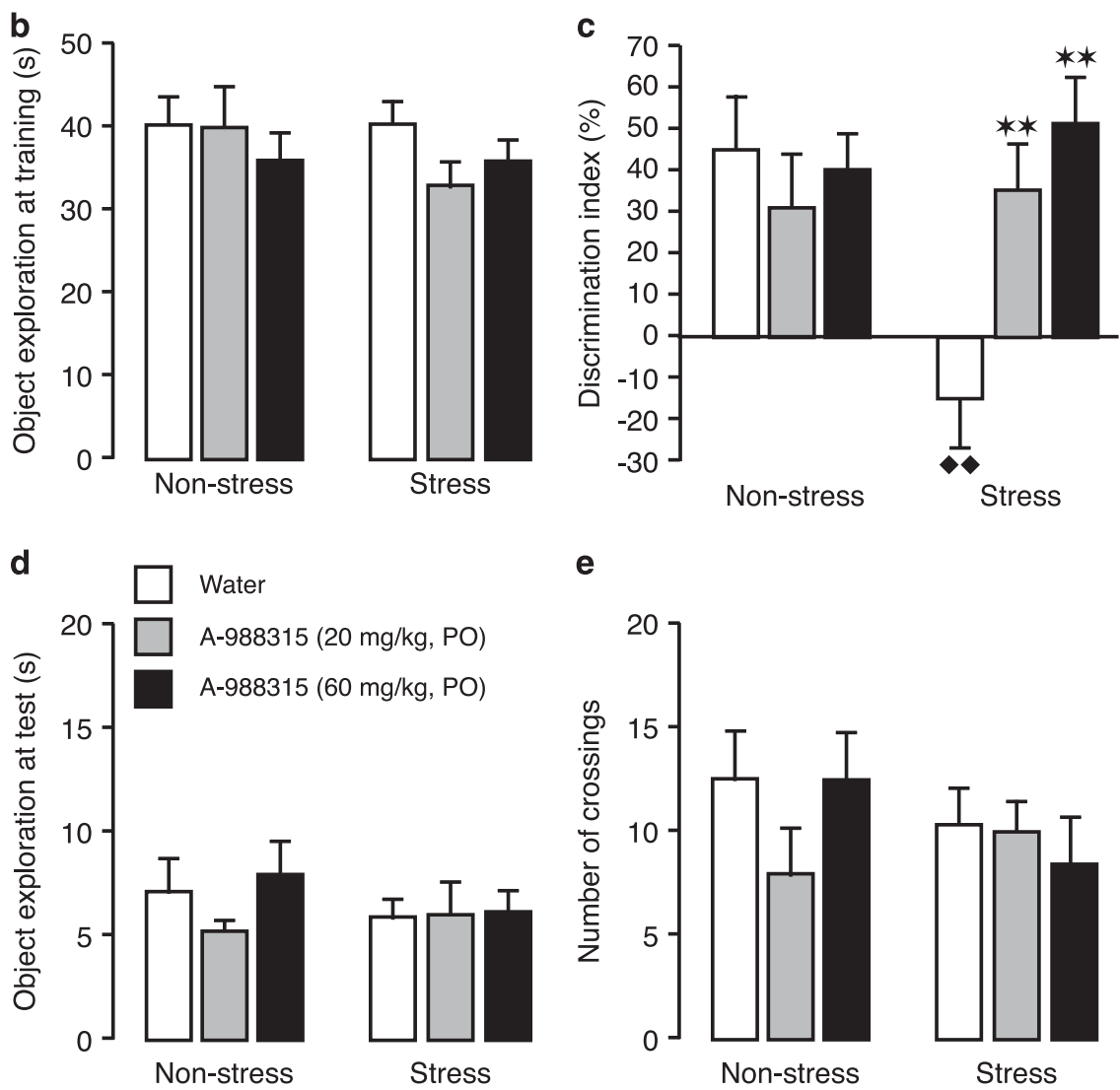

Figure 3 Effect of pretest administration of A-9883I5 on stress-induced impairment of retrieval of object-location memory. (a) Schematic illustration of training procedure, and drug and stress exposure. (b) Total time (in s) spent exploring both identical objects during the 10-min training session, before drug administration or stress exposure. (c) Discrimination index (in \%) during the 3-min retention test trial. (d) Total time (in s) spent exploring both objects during the retention test trial. (e) Total number of quadrant crossings during the retention test trial as a measure of exploration of the experimental context. All data are expressed as mean+SEM. $* * * 0.0$ I compared with the corresponding water group. ${ }^{\star} P<0.0$ I compared with the corresponding non-stress group. Number of rats per group - non-stress groups: water, $n=10 ; 20 \mathrm{mg} / \mathrm{kg}, n=10$; and $60 \mathrm{mg} / \mathrm{kg}, n=1 \mathrm{I}$; and stress groups: water, $n=1 \mid$; $20 \mathrm{mg} / \mathrm{kg}, n=10$; and $60 \mathrm{mg} / \mathrm{kg}, \mathrm{n}=11$.

of stressed rats treated with the higher dose of A-988315 did not differ significantly from those of non-stressed rats treated with the same drug dose $(P=0.12)$.

\section{DISCUSSION}

Stress-induced activation of the HPA axis and high circulating glucocorticoid levels are well known to impair the retrieval of memory processing (de Quervain et al, 2009). As AVP contributes strongly to the endocrine response to stress by stimulating V1b receptors located on the pituitary, the primary aim of the present experiments was to investigate whether oral administration of the nonpeptidergic V1b-receptor antagonist A-988315 would block stress-induced HPA-axis activation and memory retrieval impairment.
As A-988315 is a newly developed compound, and lacking any published reports, we first determined its specificity in antagonizing $\mathrm{V} 1 \mathrm{~b}$ receptors in vitro. Our findings indicate that A-988315 is a potent V1b-receptor antagonist $(\mathrm{Ki}=0.53$ $\mathrm{nM}, \mathrm{Kb}=0.1 \mathrm{nM}$ ) with high selectivity $v s$ human V1a and V2 receptors and moderate selectivity $v s$ human oxytocin receptors. Despite a sevenfold lower affinity to rat V1b receptors, A-988315 displayed a similar selectivity at rat receptors in vitro. A-988315 was able to fully block the AVP-mediated intracellular $\mathrm{Ca}^{2+}$ release in transfected cells indicating its antagonistic properties. Furthermore, the compound has a high plasma exposure and a half-life over $5 \mathrm{~h}$ indicating good pharmacokinetic properties. In addition, with an oral bioavailability of 50\%, A-988315 is a good tool compound for preclinical studies suitable for oral administration. 


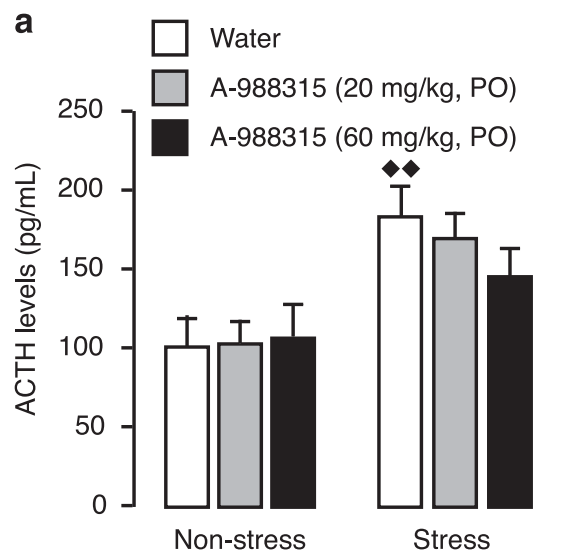

b

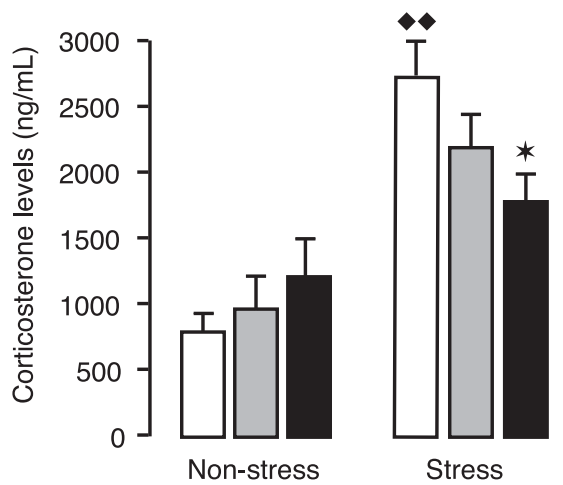

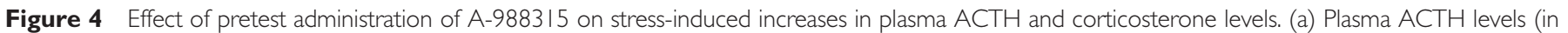

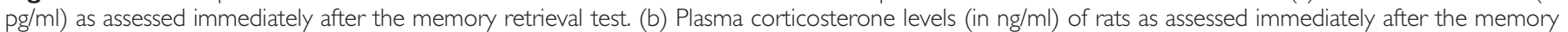

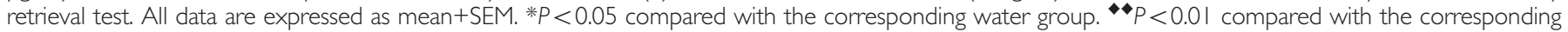

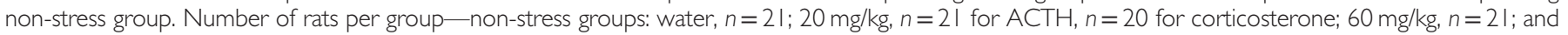
stress groups: water, $n=21 ; 20 \mathrm{mg} / \mathrm{kg}, n=19 ; 60 \mathrm{mg} / \mathrm{kg}, n=21$.

To study whether V1b-receptor antagonism is sufficient to block the stress effects on cognitive performance, A-988315 was administered orally before stress exposure, and $90 \mathrm{~min}$ before retention testing on an object-recognition or objectlocation task. A-988315 did not alter HPA-axis activity or retention performance of non-stressed rats, suggesting that V1b-receptor activation does not have a major role in determining baseline HPA-axis activity and memory. A-988315 administration dampened the stress-induced increases in ACTH and corticosterone plasma levels. This effect was most pronounced with the higher drug dose. It should be noted that at the time of retention testing and blood sampling, stress-induced corticosterone plasma levels were most likely at their peak values, whereas ACTH levels were already declining (Sarabdjitsingh et al, 2010). We opted for this 30-min time interval because of the main role of corticosterone in mediating stress effects on memory retrieval impairment (de Quervain et al, 1998). However, the selection of this time point probably also accounts for our finding that A-988315 seems to have a less dramatic effect on footshockinduced ACTH release. Most importantly, A-988315 blocked the stress-induced impairment of memory retrieval on both the object-recognition and object-location tasks. As A-988315 and the footshock stressor were given shortly before retention testing, $24 \mathrm{~h}$ after the training session, the behavioral changes are not caused by stress or drug effects on the encoding or consolidation of memory. Moreover, as A-988315 administration to either stressed or control rats did not influence the total time spent exploring the objects or experimental context, the findings indicate that V1b-receptor antagonism did not restore retention performance by altering rats' incentive to explore the objects or it did not produce any other non-specific behavioral effects. Rather, our findings are consistent with the view that A-988315 blocked stress effect on memory retrieval by attenuating the impact of stress on HPA-axis activity. In support of a role of $\mathrm{V} 1 \mathrm{~b}$ receptors in modulating HPA-axis activity in influencing stress-related behaviors, Urani et al (2011) reported that the structurally related V1b-receptor antagonist SSR149415 administered before object-recognition training blocked the effect of acute stress exposure during acquisition on short-term task performance tested $1 \mathrm{~h}$ later. Moreover, a recent genetic study in human subjects reported an association between common $\mathrm{V} 1 \mathrm{~b}$ receptor and glucocorticoid receptor gene variants in regulating HPA-axis responses to psychosocial stress in a child psychiatric population (van West et al, 2010). However, these prior studies did not specifically investigate the role of $\mathrm{V} 1 \mathrm{~b}$ receptors in regulating stress effects on the retrieval of memory. As evidence from both animal and human studies indicates sex dimorph stress effects on glucocorticoid release and memory retrieval (eg, Baran et al, 2009; Bentz et al, 2013), it is important in future studies to examine the effect of A-988315 on stress-induced HPA-axis activity and memory retrieval impairment in both male and female rats.

AVP is released during stressful conditions and acts as a direct ACTH secretagogue and also potentiates the stimulatory effects of corticotropin-releasing factor on HPA-axis activity (Aguilera and Rabadan-Diehl, 2000; Surget and Belzung, 2008). Our finding that even the higher dose of A-988315 did not fully block stress-induced HPA-axis activity suggests that the drug might have additional effects of relevance in preventing stress-induced memory retrieval impairment. In addition to a peripheral mechanism of action, the V1b receptor is expressed in hippocampal CA2 pyramidal neurons, and to some extent in the hypothalamus and the amygdala (Barberis and Tribollet, 1996; Hernando et al, 2001; Young et al, 2006). Although the large majority of studies investigating the central effects of AVP on cognitive performance have focused on V1a receptor-mediated mechanisms (de Wied et al, 1993), some evidence suggests a putative involvement of central V1b receptors in regulating certain behaviors during affective states. Rodent studies indicated that peripheral as well as central pretreatment with the V1b-receptor antagonist SSR149415 reduces anxiety- and depression-related behaviors (Griebel et al, 2002; SerradeilLe Gal et al, 2002; Roper et al, 2011). Moreover, there is some evidence that V1b-receptor activation is involved in regulating aggressive and social behaviors. It has been reported that mice lacking a functional $\mathrm{V} 1 \mathrm{~b}$ receptor are deficient in sociability and detecting social novelty (Caldwell et al, 2008; Stephenson and Caldwell, 2012; Pagani et al, 2014). It is 
unclear, however, whether these behavioral alterations are produced completely independently from the effects of V1breceptor activation on the HPA axis. Some evidence further suggests that V1b receptors might have a role in hippocampal neural plasticity (Pagani et al, 2014) and hippocampusdependent memory for temporal order (DeVito et al, 2009). Consistent with the present findings, mice lacking the V1b receptor showed normal recognition of previously explored objects and remembered where they were experienced; however, they displayed a very specific impairment in remembering the hippocampus-dependent temporal order of presentation of those objects (DeVito et al, 2009).

Our finding that stress exposure shortly before retention testing impaired the retrieval of object-recognition and object-location memory is consistent with other evidence indicating that the same footshock stress procedure impaired rats' retrieval of spatial memory in a water maze (de Quervain et al, 1998). Moreover, acute mild stress exposure to humans is known to impair delayed recall performance (Kuhlmann et al, 2005). Prior studies have, however, predominantly investigated the effects of stress or elevated glucocorticoid levels on retrieval of hippocampus-dependent 'declarative' memories in humans or spatial/contextual memories in rodents (de Quervain et al, 1998, 2000, 2003; Roozendaal et al, 2003; Het et al, 2005; Kuhlmann et al, 2005; Atsak et al, 2012). A small number of studies examined the effect of glucocorticoids on both free recall of information and recognition performance (de Quervain et al, 2000, 2003; Domes et al, 2004; Buchanan et al, 2006). One study found that stress-induced cortisol secretion impaired recognition for positive, but not negative or neutral, word associations (Domes et al, 2004), whereas the findings of the other studies indicated that stress and/or glucocorticoids significantly impaired free recall performance, yet induced only a small and nonsignificant recognition impairment. Such findings have often been interpreted in favor of a preferred influence of stress and glucocorticoids on the hippocampus (Lupien and Lepage, 2001). Alternatively, as recognition scores in human studies are often close to ceiling, it is possible that the absence of a significant stress effect was observed because the memory task had been calibrated specifically to detect impairment in free recall, and consequently, a recognition task for the same items was not sufficiently demanding. Here we provide strong evidence that stress exposure produced a large and significant impairment in the retrieval of different aspects of recognition memory. Memory for the location of an object is known to depend on the hippocampus, whereas memory for an object per se relies heavily on cortical regions and does not appear to depend critically on the hippocampus (Balderas et al, 2008; Roozendaal et al, 2010). It should be noted, however, that one study reported that although object recognition was intact after dorsal hippocampal lesions that damaged $50-75 \%$ of total hippocampal volume, it was impaired after very large lesions that encompassed $75-100 \%$ of hippocampal volume (Broadbent et al, 2004). Our findings suggest, therefore, that stress and elevated glucocorticoid levels might have a broad effect on the brain in influencing retrieval of different forms of memory. Such findings are consistent with a very recent study indicating that exposure to a social-evaluative stressor impaired retrieval of striataldependent stimulus-response memory in healthy human volunteers (Guenzel et al, 2013).
In addition to the deleterious consequences of acute stress exposure on memory retrieval, several clinical conditions, such as chronic stress, major depression, and Cushing's syndrome, are associated with persistently elevated HPA-axis activity, hypercortisolemia, and memory impairment (Starkman et al, 1992). Metyrapone is an orphan medication that holds the FDA approval for the diagnosis of Cushing's syndrome and is occasionally used off-label for short-term treatment of Cushing's syndrome before surgery. However, treatment with metyrapone or other steroidogenic inhibitors is usually discouraged because of poor tolerability and the contradictory increase in ACTH production and mineralocorticoid effects (Díez and Iglesias, 2007; Traina et al, 2013). Therefore, alternative medical treatments for the curtailing of HPA-axis activity are needed. In chronic stress, the expression of AVP in parvocellular neurons of the paraventricular nucleus and its secretion into pituitary portal circulation increase. In addition, stress regulates pituitary V1b receptors, increasing the corticotropin-releasing activity of AVP (Rabadan-Diehl et al, 1995). Future research should explore the suitability of direct antagonism of V1b receptors on the pituitary, which does not increase ACTH levels, as an alternative treatment option in patients with hyperactivation of the HPA axis (Roper et al, 2011). Such pharmacological intervention might be particularly relevant for individuals who are carriers of specific V1b receptor gene variants, associated with increased sensitivity to AVP, and display an increased vulnerability to stress-related mood and anxiety disorders (Ben-Efraim et al, 2013).

In conclusion, the present findings indicate that oral administration of the non-peptidergic V1b-receptor antagonist A-988315 before retention testing reduces the effect of stress on the HPA axis and blocks stress-induced impairment of retrieval of different aspects of recognition memory.

\section{FUNDING AND DISCLOSURE}

This work was funded by AbbVie Deutschland GmbH \& Co KG. WBH, PBJ and MMvG are full-time employees of AbbVie. A-988315 was developed by AbbVie.

\section{ACKNOWLEDGMENTS}

We thank Dr Mario Mezler for excellent discussions and contributions.

\section{REFERENCES}

Aguilera G, Rabadan-Diehl C (2000). Vasopressinergic regulation of the hypothalamic-pituitary-adrenal axis: implications for stress adaptation. Regul Pept 96: 23-29.

Atsak P, Hauer D, Campolongo P, Schelling G, McGaugh JL, Roozendaal B (2012). Glucocorticoids interact with the hippocampal endocannabinoid system in impairing retrieval of contextual fear memory. Proc Natl Acad Sci USA 109: 3504-3509.

Balderas I, Rodriguez-Ortiz CJ, Salgado-Tonda P, Chavez-Hurtado J, McGaugh JL, Bermudez-Rattoni F (2008). The consolidation of object and context recognition memory involve different regions of the temporal lobe. Learn Mem 15: 618-624.

Baran SE, Armstrong CE, Niren DC, Hanna JJ, Conrad CD (2009). Chronic stress and sex differences on the recall of fear conditioning and extinction. Neurobiol Learn Mem 91: 323-332. 
Barberis C, Tribollet E (1996). Vasopressin and oxytocin receptors in the central nervous system. Crit Rev Neurobiol 10: 119-154.

Ben-Efraim YJ, Wasserman D, Wasserman J, Sokolowski M (2013). Family-based study of AVPR1B association and interaction with stressful life events on depression and anxiety in suicide attempts. Neuropsychopharmacology 38: 1504-1511.

Bentz D, Michael T, Wilhelm FH, Hartmann FR, Kunz S, von Rohr IR et al (2013). Influence of stress on fear memory processes in an aversive differential conditioning paradigm in humans. Psychoneuroendocrinology 38: 1186-1197.

Broadbent NJ, Squire LR, Clark RE (2004). Spatial memory, recognition memory, and the hippocampus. Proc Natl Acad Sci USA 101: 14515-14520.

Buchanan TW, Tranel D, Adolphs R (2006). Impaired memory retrieval correlates with individual differences in cortisol response but not autonomic response. Learn Mem 13: 382-387.

Caldwell HK, Wersinger SR, Young WS 3rd (2008). The role of the vasopressin $1 \mathrm{~b}$ receptor in aggression and other social behaviours. Prog Brain Res 170: 65-72.

de Kloet ER, Oitzl MS, Joëls M (1999). Stress and cognition: are corticosteroids good or bad guys? Trends Neurosci 22: 422-426.

de Quervain DJ-F, Roozendaal B, McGaugh JL (1998). Stress and glucocorticoids impair retrieval of long-term spatial memory. Nature 394: 787-790.

de Quervain DJ-F, Roozendaal B, Nitsch RM, McGaugh JL, Hock C (2000). Acute cortisone administration impairs retrieval of longterm declarative memory in humans. Nat Neurosci 3: 313-314.

de Quervain DJ-F, Henke K, Aerni A, Treyer V, McGaugh JL, Berthold $\mathrm{T}$ et al (2003). Glucocorticoid-induced impairment of declarative memory retrieval is associated with reduced blood flow in the medial temporal lobe. Eur J Neurosci 17: 1296-1302.

de Quervain DJ-F, Aerni A, Schelling G, Roozendaal B (2009). Glucocorticoids and the regulation of memory in health and disease. Front Neuroendocrinol 30: 358-370.

DeVito LM, Konigsberg R, Lykken C, Sauvage M, Young WS 3rd, Eichenbaum H (2009). Vasopressin 1b receptor knock-out impairs memory for temporal order. J Neurosci 29: 2676-2683.

de Wied D, Diamant M, Fodor M (1993). Central nervous system effects of the neurohypophyseal hormones and related peptides. Front Neuroendocrinol 14: 251-302.

Díez JJ, Iglesias P (2007). Pharmacological therapy of Cushing's syndrome: drugs and indications. Mini Rev Med Chem 7: 467-480.

Domes G, Heinrichs M, Rimmele U, Reichwald U, Hautzinger M (2004). Acute stress impairs recognition for positive words-association with stress-induced cortisol secretion. Stress 7: 173-181.

Gisquet-Verrier P, Botreau F, Venero C, Sandi C (2004). Exposure to retrieval cues improves retention performance and induces changes in ACTH and corticosterone release. Psychoneuroendocrinology 29: 529-556.

Gómez F, de Kloet ER, Armario A (1998). Glucocorticoid negative feedback on the HPA axis in five inbred rat strains. Am J Physiol 274: R420-R427.

Griebel G, Simiand J, Serradeil-Le Gal C, Wagnon J, Pascal M, Scatton B et al (2002). Anxiolytic- and antidepressant-like effects of the non-peptide vasopressin $\mathrm{V} 1 \mathrm{~b}$ receptor antagonist, SSR149415, suggest an innovative approach for the treatment of stress-related disorders. Proc Natl Acad Sci USA 99: 6370-6375.

Guenzel FM, Wolf OT, Schwabe L (2013). Stress disrupts response memory retrieval. Psychoneuroendocrinology 38: 1460-1465.

Herman JP, Prewitt CM, Cullinan WE (1996). Neuronal circuit regulation of the hypothalamo-pituitary-adrenocortical stress axis. Crit Rev Neurobiol 10: 371-394.

Hernando F, Schoots O, Lolait SJ, Burbach JP (2001). Immunohistochemical localization of the vasopressin $\mathrm{V} 1 \mathrm{~b}$ receptor in the rat brain and pituitary gland: anatomical support for its involvement in the central effects of vasopressin. Endocrinology 142: 1659-1668.
Het S, Ramlow G, Wolf OT (2005). A meta-analytic review of the effects of acute cortisol administration on human memory. Psychoneuroendocrinology 30: 771-784.

Izquierdo LA, Barros DM, Medina JH, Izquierdo I (2002). Stress hormones enhance retrieval of fear conditioning acquired either one day or many months before. Behav Pharmacol 13: 203-213.

Joëls M, Baram TZ (2009). The neuro-symphony of stress. Nat Rev Neurosci 10: 459-466.

Kuhlmann S, Piel M, Wolf OT (2005). Impaired memory retrieval after psychosocial stress in healthy young men. J Neurosci 25: 2977-2982.

Lupien SJ, Lepage M (2001). Stress, memory, and the hippocampus: can't live with it, can't live without it. Behav Brain Res 127: 137-158.

McEwen BS (1998). Stress, adaptation, and disease. Allostasis and allostatic load. Ann NY Acad Sci 840: 33-44.

McEwen BS, Sapolsky RM (1995). Stress and cognitive function. Curr Opin Neurobiol 5: 205-216.

McGaugh JL, Roozendaal B (2002). Role of adrenal stress hormones in forming lasting memories in the brain. Curr Opin Neurobiol 12: 205-210.

Munson PJ, Rodbard D (1980). LIGAND: a versatile computerized approach for characterization of ligand-binding systems. Anal Biochem 107: 220-239.

Okuda S, Roozendaal B, McGaugh JL (2004). Glucocorticoid effects on object recognition memory require training-associated emotional arousal. Proc Natl Acad Sci USA 101: 853-858.

Pagani JH, Zhao M, Cui Z, Williams-Avram SK, Caruana DA, Dudek SM et al (2014). Role of the vasopressin 1 b receptor in rodent aggressive behavior and synaptic plasticity in hippocampal area CA2. Mol Psychiatry (e-pub ahead of print 27 May 2014; doi: 10.1038/mp.2014.47).

Rabadan-Diehl C, Lolait SJ, Aguilera G (1995). Regulation of pituitary vasopressin $\mathrm{V} 1 \mathrm{~b}$ receptor mRNA during stress in the rat. J Neuroendocrinol 7: 903-910.

Roozendaal B (2002). Stress and memory: opposing effects of glucocorticoids on memory consolidation and memory retrieval. Neurobiol Learn Mem 78: 578-595.

Roozendaal B, Griffith QK, Buranday J, de Quervain DJ-F, McGaugh JL (2003). The hippocampus mediates glucocorticoidinduced impairment of spatial memory retrieval: dependence on the basolateral amygdala. Proc Natl Acad Sci USA 100: 1328-1333.

Roozendaal B, Hernandez A, Cabrera SM, Hagewoud R, Malvaez M, Stefanko DP et al (2010). Membrane-associated glucocorticoid activity is necessary for modulation of long-term memory via chromatin modification. J Neurosci 30: 5037-5046.

Roozendaal B, McEwen BS, Chattarji S (2009). Stress, memory and the amygdala. Nat Rev Neurosci 10: 423-433.

Roper J, O'Carroll AM, Young W III, Lolait S (2011). The vasopressin Avpr1b receptor: molecular and pharmacological studies. Stress 14: 98-115.

Rossier J, Battenberg E, Pittman Q, Bayon A, Koda L, Miller R et al (1979). Hypothalamic enkephalin neurones may regulate the neurohypophysis. Nature 277: 653-655.

Sarabdjitsingh RA, Conway-Campbell BL, Leggett JD, Waite EJ, Meijer OC, de Kloet ER et al (2010). Stress responsiveness varies over the ultradian glucocorticoid cycle in a brain-regionspecific manner. Endocrinology 151: 5369-5379.

Serradeil-Le Gal C, Wagnon J, Simiand J, Griebel G, Lacour C, Guillon $\mathrm{G}$ et al (2002). Characterization of (2S,4R)-1-[5-chloro-1[(2,4-dimethoxyphenyl)sulfonyl]-3-(2-methoxy-phenyl)-2-oxo-2,3dihydro-1H-indol-3-yl]-4-hydroxy-N,N-dimethyl-2-pyrrolidine carboxamide (SSR149415), a selective and orally active vasopressin V1b receptor antagonist. J Pharmacol Exp Ther 300: 1122-1130.

Serradeil-Le Gal C, Wagnon J, Tonnerre B, Roux R, Garcia G, Griebel $G$ et al (2005). An overview of SSR149415, a selective nonpeptide vasopressin $\mathrm{V}(1 \mathrm{~b})$ receptor antagonist for the treatment of stress-related disorders. CNS Drug Rev 11: 53-68. 
Starkman MN, Gebarski SS, Berent S, Schteingart DE (1992). Hippocampal formation volume, memory dysfunction, and cortisol levels in patients with Cushing's syndrome. Biol Psychiatry 32: 756-765.

Stevenson EL, Caldwell HK (2012). The vasopressin $1 \mathrm{~b}$ receptor and the neural regulation of social behavior. Horm Behav 61: 277-282.

Surget A, Belzung C (2008). Involvement of vasopressin in affective disorders. Eur J Pharmacol 583: 340-349.

Schwabe L, Joëls M, Roozendaal B, Wolf OT, Oitzl MS (2012). Stress effects on memory: an update and integration. Neurosci Neurobehav Rev 36: 1740-1749.

Traina AN, Farr A, Malik R, Bingham RJ (2013). Metyrapone for long-term medical management of Cushing's syndrome. Case Rep Endocrinol 2013: 782068 .
Urani A, Philibert J, Cohen C, Griebel G (2011). The corticotropinreleasing factor 1 receptor antagonist, SSR125543, and the vasopressin 1b receptor antagonist, SSR149415, prevent stressinduced cognitive impairment in mice. Pharmacol Biochem Behav 98: 425-431.

van West D, Del-Favero J, Deboutte D, Van Broeckhoven C, Claes S (2010). Associations between common arginine vasopressin $1 \mathrm{~b}$ receptor and glucocorticoid receptor gene variants and HPA axis responses to psychosocial stress in a child psychiatric population. Psychiatry Res 179: 64-68.

Young WS, Li J, Wersinger SR, Palkovits M (2006). The vasopressin $1 \mathrm{~b}$ receptor is prominent in the hippocampal area CA2 where it is unaffected by restraint stress or adrenalectomy. Neuroscience 143: 1031-1039.

Supplementary Information accompanies the paper on the Neuropsychopharmacology website (http://www.nature.com/npp) 